\title{
Open-chain and closed-chain exercise regimes: an ultrasound investigation into the effects of exercise on the architecture of the vastus medialis oblique
}

\author{
Abdel R. Elniel ${ }^{1 \dagger}$, Claire Robertson ${ }^{2 \dagger}$, Alban Killingback ${ }^{3 \dagger}$ and Philip J. Adds ${ }^{1 *}$ \\ *Correspondence: padds@sgul.ac.uk

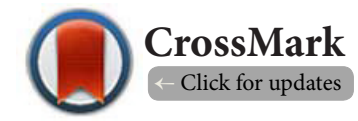 \\ ${ }^{\dagger}$ These authors contributed equally to this work. \\ 'Institute of Medical and Biomedical Education (Anatomy), St. George's, University of London, London, UK. \\ ${ }^{2}$ Wimbledon Clinics, Wimbledon, London, UK. \\ ${ }^{3}$ Department of Medical Physics and Clinical Engineering, St George's Healthcare NHS Trust, London, UK.
}

\begin{abstract}
Background: Recent discussions have compared the use of closed-chain and open-chain kinetic exercises in the management of patellofemoral pain. Literature shows disparity over the preferred method. While the clinical effectiveness of the two different approaches has been compared, there is no information in the literature on the effect of these exercise types on the vasti muscles of the thigh. This study compared the impact of open-chain and closed-chain exercise regimes on the architecture of the vastus medialis oblique.

Methods: Vastus medialis oblique architecture was measured using ultrasound in 23 young, asymptomaticvolunteers. Matched subjects were then assigned to one of two six-week exercise programmes, using either closed-chain or open-chain kinetic exercises.

$\underline{\text { Results: }}$ Both groups showed a significant increase in mean vastus medialis oblique fibre angle, (from $70.27^{\circ}$ to $74.5^{\circ}[\mathrm{OCKE}]$, and $67.5^{\circ}$ to $73.0^{\circ}[\mathrm{CCKE}], \mathrm{p}<0.001$ ); insertion length (from $21.26 \mathrm{~mm}$ to 25.98 $\mathrm{mm}[\mathrm{OCKE}]$, and $17.05 \mathrm{~mm}$ to $22.23 \mathrm{~mm}[\overline{\mathrm{CCKE}}]$. $\mathrm{p}<0.001$ ); and insertion ratio (from $41.0 \%$ to $48.46 \%$ [OCKE] and $32.0 \%$ to $41.57 \%$ [CCKE], $\mathrm{p}<0.001$ ) following 6 weeks of both open-chain and closed-chain exercises. However, no significant difference was found between the two groups.

Conclusions: The results of this study suggest that both open-chain and closed-chain exercise regimes have an equal effect on the architecture of the vastus medialis oblique after six weeks of exercise therapy.
\end{abstract}

Keywords: Vastus medialis, exercise therapy, patellofemoral pain, ultrasound

\section{Introduction}

The quadriceps femoris muscle group lies in the anterior thigh, and consists of four separate muscles: rectus femoris, vastus intermedius, vastus medialis (VM) and vastus lateralis (VL). The quadriceps femoris acts as a knee extender, inserting into the quadriceps tendon, which, through its continuation as the ligamentum patellae, inserts into the tibial tuberosity. The VM and VL also act to stabilise the patella through their insertions at the patellar margins [1].

Due largely to the angulation of the femur on the tibia (the "Q angle"), the patella tends to displace laterally when the quadriceps are forcefully contracted. The distal fibres of the VM, attached to the medial border of the patella more distally than those of the VL, help to resist lateral displacement $[2,3]$. Various cadaveric investigations have found two distinct alignments of the fibres of the VM which have led them to be identified as two distinct muscle portions, the vastus medialis oblique (VMO) and the vastus medialis longus (VML) [4-6]. There is, however, an ongoing controversy over whether the two portions are functionally separate [7-10]. A recent electromyographic investigation by Tenan et al., [11] however, appears to confirm that the VMO and VML are indeed neurologically separate muscles. 
Patellofemoral pain is a commonly-presenting condition, usually manifesting as anterior or retro-patellar knee pain, and more common in young, athletic females. Estimates of its prevalence vary from $3 \%$ to $40 \%$ of the population [12]; a study by Cowan et al., [13] estimated that $20 \%$ of the student population are affected. Although the pathogenesis of PFP is generally agreed to be multi-factorial, it is thought that patella maltracking plays a key role [14]. Weakness in the VMO can lead to lateral deviation of the patella, leading to stress on the patella and peripatellar tissue resulting in PFP $[15,16]$. Although VMO insufficiency has not been shown to be the primary cause of PFP, the current breadth of data supporting VMO involvement in patellofemoral pain has affirmed its significance as a contributing factor. As a consequence, conservative therapy aims to strengthen the quadriceps, and in particular the VMO, via physical therapy [17]. Targeted exercises have been shown to increase the fibre angle and insertion level of the VMO, thereby increasing the medialising effect on the patella of contraction of the VM [18].

There has been discussion as to which type of exercise is more effective: "closed-chain" (where the distal end of the limb is fixed) or "open-chain", where the distal end of the limb is free to move. Studies have generally shown an improvement in symptoms and improved functionality in PFP sufferers following both OCKE and CCKE exercises, though there have been differing reports as to which was the more effective [19-22]. While there is conflicting evidence as to the relative effectiveness of the two types of exercise, there is no information currently available on the relative effects of OCKE and CCKE on the actual morphology of the VMO.

In this study we used ultrasound - a safe, non-invasive imaging modality, to investigate the fibre angle and insertion level of the VMO in a group of 23 young, asymptomatic male volunteers. Asymptomatic volunteers were chosen in order not to compound the variables with the effects of PFP on the individuals' ability to carry out the exercises. The application of ultrasound in investigations into skeletal muscle architecture has been demonstrated in multiple studies (e.g., $[23,24])$. The method used here has been validated [25], and has been used in previous investigations into the VMO [18,26-29].

The purpose of this study was to compare the effects of open-chain and closed-chain kinetic exercises (OCKE and (CKE) on the architecture of the VMO following a six-week exercise programme, in two groups of volunteers. Ultrasound was used to measure the VMO fibre angle and insertion level in the subjects both before and after the exercise programme.

\section{Methods \\ Study design}

The participants were split into two equal groups. Each group then undertook a six-week quadriceps training programme using either OCKE or CCKE exercises. The participants were scanned with ultrasound before and after the exercise programme. The VMO fibre angle and insertion level were recorded.

\section{Participants}

Twenty-three young, asymptomatic male volunteers were recruited to take part in this study. The study was approved by the local Ethics Committee, and all subjects gave informed consent prior to the initial examination. Details of the subjects are given in Table 1. The sample size was in line with similar studies in the literature (e.g., $[18,22,23])$.

Exclusion criteria: volunteers were excluded if they reportedany current or previous knee pain, previous knee surgery, quadriceps injury, a Tegner activity score $>3$, or gym leg training $\geq$ once a week, or if they had any lower limb deformity or abnormality. The Tegner activity scale is a validated 10-point scale that quantifies an individual's level of activity [30]. For this study, participants were required to be sedentary (i.e., with a Tegner score below 3 ), so that any observed changes could be attributed with confidence to the exercise regime. Volunteers who trained regularly at the gym were also excluded, for the same reason (the Tegner scale does not include gym activity).

\section{Procedure}

The ultrasound technique used in this study followed the method that has been validated and described in several previous studies [18,25-29]. Participants were positioned supine on the examination couch; a pillow was placed under the ankles to immobilise the lower limbs. The superior border and apex of the patella were palpated and marked using a skin pen and transparent ruler. Clarke CM145 digital callipers (accurate to $0.01 \mathrm{~mm}$ ) were then used to measure the patella length. The callipers were then used to determine the mid-point of the patella (width divided by 2), which was marked. The femoral axis was then marked by placing a stainless steel metre ruler from the subject's anterior superior iliac spine (ASIS) to the midpoint of the patella. A line indicating the femoral axis was marked along the patella.

Volunteers underwent an initial ultrasound scan to determine base-line measurements of fibre angle and VMO insertion level with a Philips iU22 ultrasound machine, with 15-7 linear-array probe. In order to eliminate inter-rater vari-

Table 1. Mean $( \pm \mathrm{SD})$ anthropometric data of CCKE and OCKE groups.

\begin{tabular}{llllll}
\hline & Weight $(\mathrm{Kg})$ & Height $(\mathbf{m})$ & BMI $\left(\mathrm{Kg} / \mathbf{m}^{2}\right)$ & Age & Tegner Score \\
\hline OCKE $(\mathrm{n}=11)$ & $78.32( \pm 14.52)$ & $1.81( \pm 0.072)$ & $23.8( \pm 3.2)$ & $20.7( \pm 1.35)$ & $2.0( \pm 0.99)$ \\
CCKE $(\mathrm{n}=12)$ & $74.03( \pm 10.01)$ & $1.78( \pm 0.047)$ & $23.39( \pm 3.2)$ & $19.92( \pm 1.0)$ & $2.1( \pm 0.9)$ \\
Total $(\mathrm{n}=23)$ & $76.08( \pm 12.28)$ & $1.79( \pm 0.06)$ & $23.58( \pm 3.13)$ & $20.3( \pm 1.22)$ & $2.05( \pm 0.94)$ \\
\hline
\end{tabular}

The differences between the means for the two test groups were not significant ( $p>0.05$ in all cases). 
ability, the same operator carried out all the scans in this study. Transmission gel was applied, and the probe was placed horizontally on the subject's thigh, just superomedial to the superior patellar border. The probe was moved proximally until a substantial number of VMO muscle fibres could be seen on the monitor. The probe was rotated anti-clockwise for the right knee and clockwise for the left knee, until the fibres appeared parallel to one another. Care was taken to avoid undue applying undue pressure which could distort the underlying soft tissue (Figure 1).

At the point of maximum angle, a screenshot was taken of the image and the ends of the probe were marked on the subject's thigh. The ultrasound gel was wiped from the subject's knee and a line was drawn through the two pen markings, and continued to intersect with the femoral axis. The angle was measured using a protractor (resolution $1^{\circ}$ ) (Figure 2).

The probe was placed horizontally on the thigh once again, just medial to the superior patellar border. With the VMO fibres apparent on the monitor, the probe was tracked distally until the fibres of the VMO were no longer visible. The point at which muscle fibres become no longer visible indicated the end of the muscle's distal attachment (Figure 3). This was marked, then the distance between the superior patellar border and marked line was measured using the digital callipers. This measurement represents the insertion length. Dividing this value by the patella length gives the insertion ratio, which can be presented as a percentage.

Participants (matched for height and BMI) were randomly allocated to one of two groups (using an on-line random number generator), and assigned either an open-chain (OCKE) or closed-chain (CCKE) kinetic exercise programme, every other day for six weeks $[17,31]$. Each group was given a choice of one of two very similar exercises to complete throughout the study. Exercises were chosen that were easy to perform at home, were commonly used in clinical practice, and were

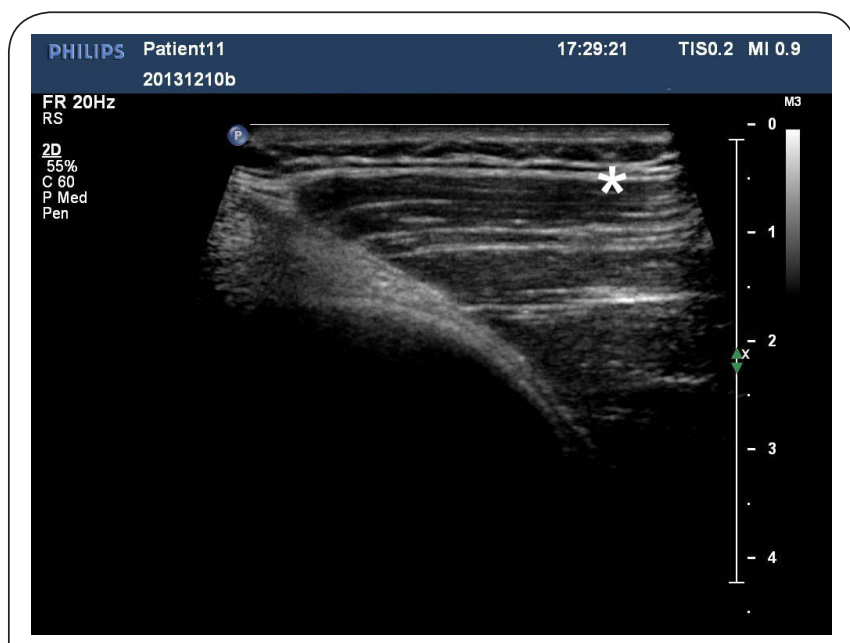

Figure 1. Ultrasound image.

${ }^{\star}$ Indicates parallel fibres of VMO.

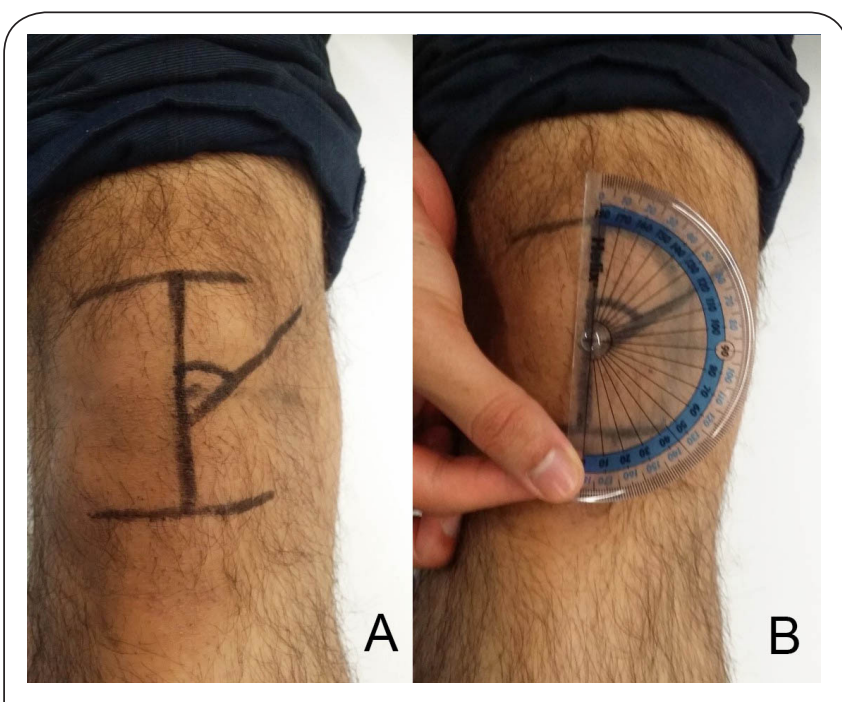

Figure 2. (A) The points marked either side of the probe are used to draw a line to the femoral axis; (B) The angle between the two lines is measured using a protractor.

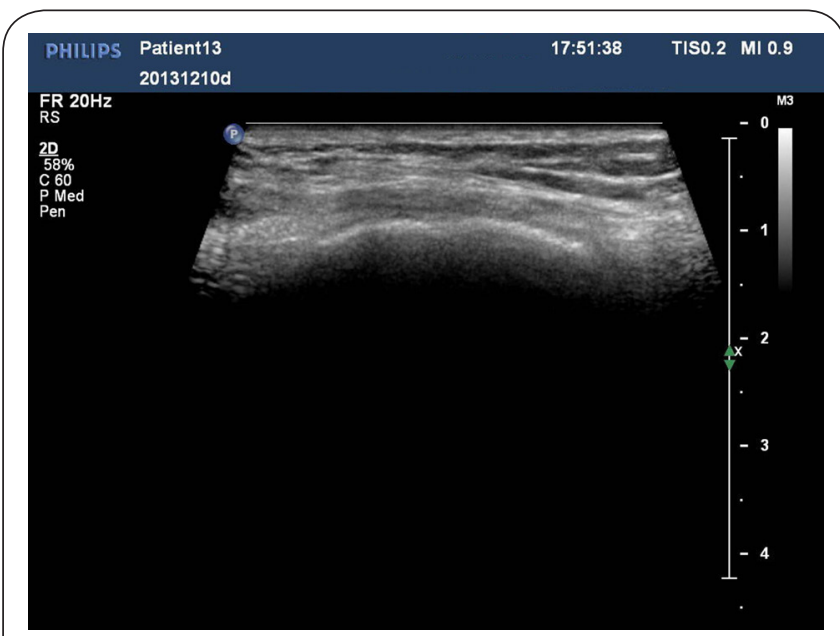

Figure 3. Ultrasound image. VMO fibres are no longer visible indicating the distal limit of insertion (compare with Figure 1 above).

aimed to produce the same effect of light fatigue in both groups [32]. "Fatigue" was described as shaking or a sense of tiring from the muscle as perceived by the subject. All individuals were given an instruction sheet and demonstrations from a specialist Physiotherapist on how to complete the exercises. Participants were asked to complete a diary to monitor compliance.

For the OCKE programme, subjects had a choice of two exercises: supine straight leg raise or supine isometric quadriceps contractions, to be repeated until the first signs of fatigue. The time to reach fatigue was expected to vary between individuals, and to take longer as the study progressed. Exercises were to be carried out on each leg alternately. Data from all limbs were averaged. 
Elniel et al. Physical Therapy and Rehabilitation 2017,

http://www.hoajonline.com/journals/pdf/2055-2386-4-3.pdf

For the CCKE regime, the two exercises were:

1. With their hands placed firmly on a stable surface, subjects were asked to stand fully on one leg, with the other leg flexed to $90^{\circ}$ at the knee. They then had to squat down to approximately $20^{\circ}$ and hold this position for four seconds. They then returned to their initial stance for a four second rest period. This was repeated until the first signs of fatigue. They then swapped legs and repeated the exercise (Figure 4).

2. For this exercise, subjects used a stable surface, no greater than $10 \mathrm{~cm}$ high, ideally the bottom step of a set of stairs or a small step ladder. With one leg on the step, subjects were asked to slowly lower themselves until the other leg just touched the floor and then return to the start position. Subjects were asked to focus on using the muscles in the anterior thigh to control the descent. This exercise was completed until patients felt the initial signs of fatigue; once completed they were asked to swap legs and repeat (Figure 5).

On completion of the six-week exercise programme, subjects were re-scanned. The patella was re-measured to provide an assessment of operator reliability.

\section{Statistical analysis}

Statistical analysis was carried out using SPSS v24.0 (IBM SPSS

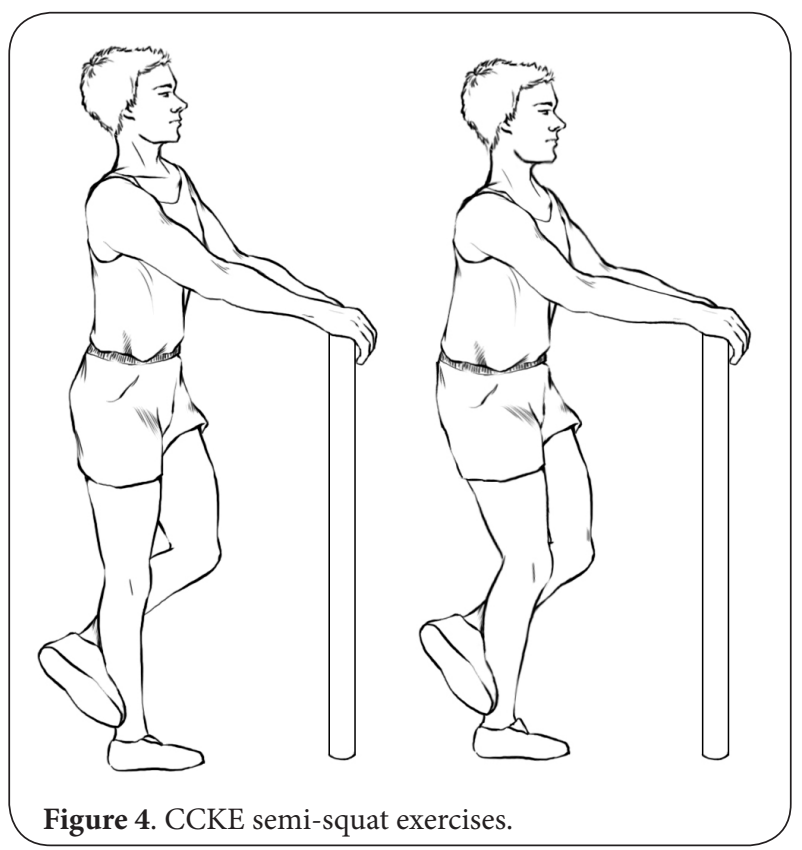

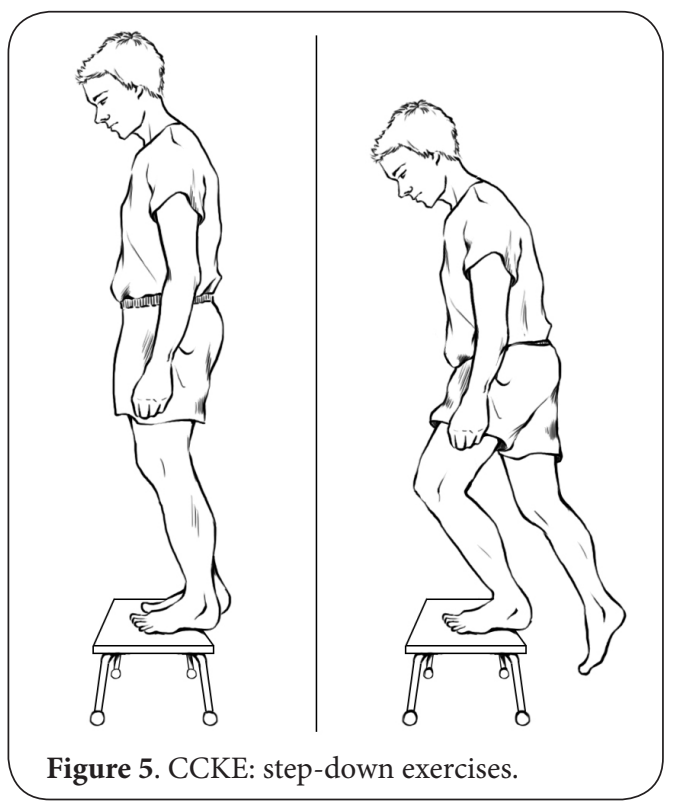

Statistics). An independent sample t-test was used to compare the means of the baseline data for the two test groups, and the changes in VMO fibre angle, insertion length and insertion ratio for OCKE versus CCKE following exercise. A paired t-test was used to evaluate significant changes, before and after intervention. A $P$-value of less than 0.05 was taken to denote significance. The correlation coefficient was used to test correlation between initial values and the amount of change after intervention. For the test-retest reliability assessment, Pearson's correlation coefficient for the two sets of patella length measurements was calculated.

\section{Results}

Twenty-three male volunteer stook part in the study. Anthropometric data for the participants are summarised above (Table 1). There were found to be no significant differences between the means of the baseline values for the two experimental groups ( $p>0.05)$. Both groups showed a significant increase in VMO fibre angle after exercise $(p<0.001)$. A mean VMO angle change of $4.65^{\circ}( \pm 3.36)$ was observed in the OCKE group. The CCKE-only group showed a mean change of $5.73^{\circ}$ $( \pm 2.87)$. The difference in mean angle change between the two groups was not significant $(p=0.31)$ (Table 2).

A mean increase in insertion length (i.e., the length of VMO inserted onto the patella) of $4.31 \mathrm{~mm}( \pm 5.33)$ was seen

Table 2. Mean $( \pm \mathrm{SD}) \mathrm{VMO}$ fibre angle, insertion length and insertion ratio before and after exercise programme.

\begin{tabular}{|c|c|c|c|c|c|c|c|}
\hline & \multicolumn{3}{|c|}{ OCKE } & \multicolumn{3}{|c|}{ CCKE } & \multirow[b]{2}{*}{$\begin{array}{l}\text { P-value OCKE } \\
\text { vs CCKE }\end{array}$} \\
\hline & Initial (mean) & $\begin{array}{l}\text { Post-exercise } \\
\text { (mean) }\end{array}$ & Change & Initial (mean) & $\begin{array}{l}\text { Post-exercise } \\
\text { (mean) }\end{array}$ & Change & \\
\hline Fibre angle $\left(^{\circ}\right)$ & $70.27( \pm 8.43)$ & $74.5( \pm 6.66)$ & $4.65 \pm 3.36$ & $67.5( \pm 7.85)$ & $73.0( \pm 4.85)$ & $5.73( \pm 2.87)$ & 0.31 \\
\hline Insertion length (mm) & $21.26( \pm 4.78)$ & $25.98( \pm 4.59)$ & $4.31 \pm 5.33$ & $17.05( \pm 5.47)$ & $22.23( \pm 5.91)$ & $4.63( \pm 2.92)$ & 0.82 \\
\hline Insertion ratio (\%) & $41.0( \pm 9.0)$ & $48.46( \pm 7.84)$ & $6.15 \pm 9.89$ & $32.0( \pm 10.0)$ & $41.57( \pm 10.51)$ & $7.97( \pm 4.91)$ & 0.48 \\
\hline
\end{tabular}


in the OCKE group. In the CCKE group the mean increase was $4.63 \mathrm{~mm}( \pm 2.92)(p<0.001)$. No significant difference was observed between the two interventions $(p=0.82)$ (Table 2).

The mean increase in insertion ratio (i.e., the insertion length expressed as a percentage of patella length) in the OCKE group was $6.15 \%( \pm 9.89)$. In the CCKE group, the mean increase was $7.97 \%( \pm 4.91)(p<0.001)$. No significant difference was observed between the two interventions $(p=0.48)$ (Table 2).

There appeared to be little correlation between fibre angle change and insertion length change $\left(R^{2}=0.0606\right)$; some participants showed a significant change in insertion length without a substantial increase in VMO fibre angle and vice versa.

There was an observable inverse relationship across all participants in the study, between initial fibre angle and fibre angle change, where by individuals with a smaller initial fibre angle showed the greatest amount of angle change following the exercise regime $\left(R^{2}=-0.59\right)$. Similarly, individuals with a smaller initial insertion length showed a greater change following exercise, though the correlation was less marked $\left(R^{2}=-0.17\right)$.

The mean self-reported compliance was $67 \%( \pm 3.36)$ in the OCKE group, and $68 \%( \pm 2.87)$ in the CCKE group.

\section{Test-retest reliability assessment}

The coefficient of correlation for the two sets of patella length measurements was 0.86 , indicating good reliability.

\section{Discussion}

This study was designed to investigate the effect of open and closed-chain kinetic exercises on VMO architecture. There is a disparity in the literature regarding the relative merits of OCKE and CCKE in treatment of PFP. Studies have shown there to be a significant improvement in functionality in symptomatic PFP patients following both treatments, with most authors favouring CCKE $[19-21,31]$. What has not been available hitherto, however, is evidence of whether, and to what extent, these treatments can lead to observable differences in the architecture of the VMO.

The exercises chosen for this study were adapted from those used in previous studies on OCKE and CCKE $[18,32,33]$. It was thought that compliance would be improved if participants could choose their preferred exercise, so they were allowed to choose from two exercises throughout the six week period.

Escamilla et al., [34] studied the biomechanics of the knee during CCKE squats and leg presses, and OCKE leg extensions. They reported that CCKE recruited more muscle groups and was shown to be more effective at employing the vasti muscles. OCKE, however, produced greater rectus femoris activity, and they therefore concluded that OCKE may be more effective than CCKE at overall quadriceps development.

We found very little difference in mean angle change between the OCKE and CCKE exercise programmes. Although the CCKE group achieved a slightly greater average increase $\left(4.65^{\circ}\right.$ compared to $\left.5.73^{\circ}\right)$, the difference was not statistically significant ( $p=0.31)$. While increases in fibre angle following resistance training are to be expected in pennate muscles [35-37], no previous studies have investigated the architecture of the vasti muscles following these two interventions. From a clinical perspective, the results suggest that preference for semi-squat exercises over straight leg raises may be misplaced. This was founded upon the idea that CCKE would have greater impact on the VM, and was supported by increased thigh circumference in the CCKE study group [33].

Of course, CCKE may have more impact on PFPS than simply by strengthening vastus medialis: Petersen et al., [14] outline the role of hip abductors, hamstring muscles and the lower back in patellar stress; Escamilla et al., [34] observed twice as much hamstring activity in squat exercises compared to leg extensions. Squat exercises also involve core and back muscle to stabilise the body on descent. The multi-target nature of such a CCKE regimen may therefore bring more benefits to PFPS patients than just strengthening the VMO.

Witvrouw et al. [21], however, found long-term outcomes equally good following both types of exercise. Based upon these findings, it may be that combined OCKE and CCKE therapy would be most effective. The results reported here tend to support this.

A negative correlation was observed between initial angle and degree of angle change $\left(R^{2}=-0.59\right)$, such thatparticipants with a smaller initial angle saw greater angle change compared to those with larger initial angles. Jan et al., [27] reported smaller VMO fibre angle in PFPS patients relative to controls, though there is wide variation. The findings reported here tend to support the suggestion by Khoshkhoo et al., [18] that a simple ultrasound screening test could be employed in clinic to identify patients with a low initial fibre angle, for whom VMO strengthening exercises might be most effective.

There was a mean insertion length increase of $4.31 \mathrm{~mm}$ $( \pm 5.33)$ in the OCKE group and $4.63 \mathrm{~mm}( \pm 2.92)$ in the CCKE group. While both studies showed significant increases, there was no significant difference between the exercise types $(p=0.82)$. Increased insertion length is a phenomenon often associated with an increase in muscle volume [27], which is supported by the results reported here. A weak inverse relationship was noted between initial insertion length and insertion length change $\left(R^{2}=-0.17\right)$, which echoes the relationship seen in fibre angle change The mean insertion ratio (i.e., insertion length/patella length expressed as a percentage) increased by $6.15 \% \pm 9.89$ in the OCKE group, and by $7.97 \%$ \pm 4.91 in the CCKE group. There was no significance between the two groups $(p=0.48)$.

A study by Benjafield et al., [29] found an average insertion ratio of $43.0 \%$ in athletic individuals, compared to $39.5 \%$ in sedentary individuals (the overall initial ratio in our study was $36.83 \%$, which supports the low Tegner scores reported by the participants). The increase in insertion length, and hence increased ratio, following the exercise programme, enables a greater medial pull on the patella by the VMO, facilitating 
Elniel et al. Physical Therapy and Rehabilitation 2017,

correction of the lateral tilt and shift often seen in PFPS.

It is important to consider the level of compliance in a study of this type. The OCKE group had an average self-reported compliance of $67 \%$ compared to $68 \%$ amongst the CCKE group. Although both are closely similar, the standard deviation in the CCKE group (2.87) was smaller than the OCKE group (3.36), signifying greater consistency, which may have influenced the outcome of the exercises.

Despite the reported validityof the in vivo ultrasound method [25], there may bea degree of subjectivity in interpretation of the ultrasound image. The reliability of the results was enhanced by having all the measurements taken by the same investigator throughout the study. The test-retest results for this observer showed a high level of reliability. While the cohort size of twenty-three individuals is comparable to other studies in the literature, a larger sample size would have strengthened the study, particularly in view of the relatively large standard deviation seen in some of the data.

\section{Conclusions}

Both OCKE and CCKE exercise regimes brought about significant changes in the muscle architecture of the study subjects following six weeks of exercise; however, the difference between the two groups was not significant. We can conclude, therefore, that the difference between the effects of OCKE and CCKE regimes was insignificant in all the parameters of VMO morphology investigated here, and that in terms of bringing about a measureable change in the fibre angle, insertion level, and insertion ratio of the VMO, both types of exercise are equally effective.

\section{List of abbreviations}

CCKE: Closed-chain kinetic exercise

OCKE: Open-chain kinetic exercise

PFP: Patellofemoral pain

VL: Vastus lateralis

VM: Vastus medialis

VML: Vastus medialis longus

VMO: Vastus medialis oblique

\section{Competing interests}

The authors declare that they have no competing interests.

\section{Authors' contributions}

\begin{tabular}{|l|c|c|c|c|}
\hline Authors' contributions & ARE & CR & AK & PJA \\
\hline Research concept and design & -- & $\checkmark$ & -- & -- \\
\hline Collection and/or assembly of data & $\checkmark$ & -- & $\checkmark$ & -- \\
\hline Data analysis and interpretation & $\checkmark$ & $\checkmark$ & $\checkmark$ & $\checkmark$ \\
\hline Writing the article & $\checkmark$ & $\checkmark$ & & $\checkmark$ \\
\hline Critical revision of the article & $\checkmark$ & $\checkmark$ & $\checkmark$ & $\checkmark$ \\
\hline Final approval of article & $\checkmark$ & $\checkmark$ & $\checkmark$ & $\checkmark$ \\
\hline Statistical analysis & -- & -- & $\checkmark$ & $\checkmark$ \\
\hline
\end{tabular}

\section{Acknowledgement}

The authors would like to thank Rachel Mead for the drawings.
Publication history

Editor: Gordon John Alderink, Grand Valley State University, USA. Received: 07-Feb-2017 Final Revised: 27-Apr-2017

Accepted: 23-May-2017 Published: 09-Jun-2017

\section{References}

1. Moore KL, Dalley AF and Agur AMR. Clinically Orientated Anatomy, $7^{\text {th }}$ edition. 2014; 547.

2. Gosling JA, Harris PF, Whitmore I and Willan PLT. Human Anatomy: Color Atlas and Text, 4th edition. 2002; 270.

3. Katchburian MV, Bull AM, Shih YF, Heatley FW and Amis AA. Measurement of patellar tracking: assessment and analysis of the literature. Clin Orthop Relat Res. 2003; 241-59. | Article I PubMed

4. Scharf W, Weinstabl R and Orthner E. [Anatomical separation and clinical importance of two different parts of the vastus medialis muscle]. Acta Anat (Basel). 1985; 123:108-11. | PubMed

5. Travnik L, Pernus F and Erzen I. Histochemical and morphometric characteristics of the normal human vastus medialis longus and vastus medialis obliquus muscles. J Anat. 1995; 187 ( Pt 2):403-11. | PubMed Abstract | PubMed FullText

6. Skinner EJ and Adds PJ. Vastus medialis: a reappraisal of VMO and VML. J Phys Ther Sci. 2012; 24:475-479.

7. Lieb FJ and Perry J. Quadriceps function. An anatomical and mechanical study using amputated limbs. J Bone Joint Surg Am. 1968; 50:1535-48. | Article | PubMed

8. Hubbard JK, Sampson HW and Elledge JR. Prevalence and morphology of the vastus medialis oblique muscle in human cadavers. Anat Rec. 1997; 249:135-42. | PubMed

9. Nozic M, Mitchell J and de Klerk D. A comparison of the proximal and distal parts of the vastus medialis muscle. Aust J Physiother. 1997; 43:277-281. | Article | PubMed

10. Peeler J, Cooper J, Porter MM, Thliveris JA and Anderson JE. Structural parameters of the vastus medialis muscle. Clin Anat. 2005; 18:281-9. | Article I PubMed

11. Tenan MS, Hackney AC and Griffin L. Entrainment of vastus medialis complex activity differs between genders. Muscle Nerve. 2016; 53:63340. | Article | PubMed

12. Callaghan MJ and Selfe J. Has the incidence or prevalence of patellofemoral pain in the general population in the United Kingdom been properly evaluated? Phys Ther Sport. 2007; 8:37-43. | Article

13. Cowan SM, Bennell KL, Hodges PW, Crossley KM and McConnell J. Delayed onset of electromyographic activity of vastus medialis obliquus relative to vastus lateralis in subjects with patellofemoral pain syndrome. Arch Phys Med Rehabil. 2001; 82:183-9. | Article | PubMed

14. Petersen W, Ellerman A, Gosele-Koppenburg A, Best R, Rembitzki IV, Bruggerman G-P and Liebau C. Patellofemoral pain syndrome. Knee Surg Sport Tr A. 2014; 22:2264-2274.

15. Amis AA. Current concepts on anatomy and biomechanics of patellar stability. Sports Med Arthrosc. 2007; 15:48-56. | Article | PubMed

16. Wilson T. The measurement of patellar alignment in patellofemoral pain syndrome: are we confusing assumptions with evidence? J Orthop Sports Phys Ther. 2007; 37:330-41. | Article | PubMed

17. Crossley K, Bennell K, Green S, Cowan S and McConnell J. Physical therapy for patellofemoral pain: a randomized, double-blinded, placebo-controlled trial. Am J Sports Med. 2002; 30:857-65. | Article | PubMed

18. Khoshkhoo M, Killingback A, Robertson CJ and Adds PJ. The effect of exercise on vastus medialis oblique muscle architecture: An ultrasound investigation. Clin Anat. 2016; 29:752-8. | Article | PubMed

19. Doucette SA and Child DD. The effect of open and closed chain exercise and knee joint position on patellar tracking in lateral patellar compression syndrome. J Orthop Sports Phys Ther. 1996; 23:104-10. | Article I PubMed

20. Stiene HA, Brosky T, Reinking MF, Nyland J and Mason MB. A comparison 
Elniel et al. Physical Therapy and Rehabilitation 2017,

of closed kinetic chain and isokinetic joint isolation exercise in patients with patellofemoral dysfunction. J Orthop Sports Phys Ther. 1996; 24:136-41. | Article | PubMed

21. Witvrouw E, Danneels L, Van Tiggelen D, Willems TM and Cambier D. Open versus closed kinetic chain exercises in patellofemoral pain: a 5-year prospective randomized study. Am J Sports Med. 2004; 32:112230. I Article I PubMed

22. Irish SE, Millward AJ, Wride J, Haas BM and Shum GL. The effect of closed-kinetic chain exercises and open-kinetic chain exercise on the muscle activity of vastus medialis oblique and vastus lateralis. J Strength Cond Res. 2010; 24:1256-62. | Article | PubMed

23. Aagaard P, Andersen JL, Dyhre-Poulsen P, Leffers AM, Wagner A, Magnusson SP, Halkjaer-Kristensen J and Simonsen EB. A mechanism for increased contractile strength of human pennate muscle in response to strength training: changes in muscle architecture. J Physiol. 2001; 534:613-23. | Article | PubMed Abstract | PubMed FullText

24. e Lima KM, Carneiro SP, Alves Dde S, Peixinho CC and de Oliveira LF. Assessment of muscle architecture of the biceps femoris and vastus lateralis by ultrasound after a chronic stretching program. Clin J Sport Med. 2015; 25:55-60. | Article | PubMed

25. Engelina S, Robertson CJ, Moggridge J, Killingback A and Adds P. Using ultrasound to measure the fibre angle of vastus medialis oblique: a cadaveric validation study. Knee. 2014; 21:107-11. | Article | PubMed

26. Engelina S, Antonios T, Robertson CJ, Killingback A and Adds PJ. Ultrasound investigation of vastus medialis oblique muscle architecture: an in vivo study. Clin Anat. 2014; 27:1076-84. | Article | PubMed

27. Jan $\mathrm{MH}$, Lin $\mathrm{DH}$, Lin JJ, Lin CH, Cheng CK and Lin YF. Differences in sonographic characteristics of the vastus medialis obliquus between patients with patellofemoral pain syndrome and healthy adults. Am J Sports Med. 2009; 37:1743-9. | Article | PubMed

28. Lin YF, Lin JJ, Cheng CK, Lin DH and Jan MH. Association between sonographic morphology of vastus medialis obliquus and patellar alignment in patients with patellofemoral pain syndrome. J Orthop Sports Phys Ther. 2008; 38:196-202. | Article I PubMed

29. Benjafield AJ, Killingback A, Robertson CJ and Adds PJ. An investigation into the architecture of the vastus medialis oblique muscle in athletic and sedentary individuals: an in vivo ultrasound study. Clin Anat. 2015; 28:262-8. | Article | PubMed

30. Tegner $Y$ and Lysholm J. Rating systems in the evaluation of knee ligament injuries. Clin Orthop Relat Res. 1985; 43-9. I PubMed

31. Witvrouw E, Lysens R, Bellemans J, Peers K and Vanderstraeten G. Open Versus Closed Kinetic Chain Exercises for Patellofemoral Pain. Am J Sports Med. 2000; 28:687-694. | Article I PubMed

32. Sandor R and Fowlkes A. Knee rehabilitation: exercise instruction: Palo Alto: Camino Medical Group. 2007.

33. Bakhtiary $\mathrm{AH}$ and Fatemi E. Open versus closed kinetic chain exercises for patellar chondromalacia. Br J Sports Med. 2008; 42:99-102. | Article I PubMed

34. Escamilla RF, Fleisig GS, Zheng N, Barrentine SW, Wilk KE and Andrews JR. Biomechanics of the knee during closed kinetic chain and open kinetic chain exercises. Med Sci Sports Exerc. 1998; 30:556-69. | Article | PubMed

35. Jones DA and Rutherford OM. Human muscle strength training: the effects of three different regimens and the nature of the resultant changes. J Physiol. 1987; 391:1-11. | Article | PubMed Abstract | PubMed FullText

36. Seynnes OR, de Boer M and Narici MV. Early skeletal muscle hypertrophy and architectural changes in response to high-intensity resistance training. J Appl Physiol (1985). 2007; 102:368-73. | Article | PubMed

37. Franchi MV, Atherton PJ, Reeves ND, Fluck M, Williams J, Mitchell WK, Selby A, Beltran Valls RM and Narici MV. Architectural, functional and molecular responses to concentric and eccentric loading in human skeletal muscle. Acta Physiol (Oxf). 2014; 210:642-54. | Article | PubMed

\section{Citation:}

Elniel AR, Robertson C, Killingback A and Adds PJ. Open-chain and closed-chain exercise regimes: an ultrasound investigation into the effects of exercise on the architecture of the vastus medialis oblique.

Phys Ther Rehabil. 2017; 4:3.

http://dx.doi.org/10.7243/2055-2386-4-3 